\title{
RESENHA
}

\section{Emociones infantiles: evolución, evaluación y prevención}

\author{
Cloves Amorim \\ Pontifícia Universidade Católica do Paraná
}

BARRIO, María Victoria del (2002). Emociones Infantiles: evolución, evaluación y Prevención. Madri: Edições Pirâmide.

A obra foi organizada em seis capítulos; na introdução a autora destaca que no passado todos os livros e artigos sobre emoção começavam com os autores se queixando da pouca atenção dedicada ao tema, afirmando que atualmente, este cenário tem se modificado. Após os capítulos há uma sessão de leituras recomendadas. Finalmente na Bibliografia são encontradas 270 referências ao longo de 22 páginas.

A autora, María Victoria del Barrio, é professora titular da Universidade de Ensino à Distância, em Madri, na área de Personalidade, Avaliação e Tratamentos Psicológicos. É Expert em avaliação e Psicopatologia infantil, especialmente na área de alterações emocionais, tais como depressão, ansiedade e agressividade. Autora de inúmeros artigos publicados em revistas importantes na comunidade científica e participante dos congressos mais relevantes da área.

No capítulo 1, "Las emociones, bases teóricas, función y tipos" apresenta um quadro geral do desenvolvimento das emoções infantis considerando as pesquisas mais relevantes desenvolvidas na área. Ao abordar as distintas perspectivas teóricas, cita Leventhal e Tomarken (1986) que classificam as teorias em três grupos: 1) Evolutivas (Darwin, McDougall, Izard \& Plutchik), 2) Respostas orgânicas (James \& Schachter) e 3) Centrais e cognitivas (Sully, Russel \& Schachter). Nesse capítulo apresenta as contribuições de cada perspectiva.

"La emocióm en el niño y su implantación evolutiva" é o título do capítulo 2. Inicia o capítulo afirmando que os especialistas concordam em sublinhar o caráter evolutivo das emoções infantis, mas existem poucos estudos sistemáticos e empíricos sobre o tema. Em seguida apresenta os elementos que representam um importante papel na constituição e implantação das vivências emocionais: o temperamento, a família e a sociedade. Da página 49 a 52, elabora um quadro sintético sobre o aparecimento da expressão das emoções nas crianças. Nesse quadro se descreve o tipo de emoção, o(s) autor(es) do estudo, a forma de expressão e a idade. As emoções mais citadas no quadro são: alegria, ira, amor, medo, surpresa, desgosto, apego e vergonha. Segundo a autora todos os estudos coincidem em afirmar que, nos primeiros meses, os signos das emoções são mais globais e difusos, mas à medida que a criança cresce, vão se tornando mais específicos e diminuem as confusões de interpretação para o espectador. A partir da página 54 , descreve-se o histórico da percepção que a criança tem da emoção no outro, e nas páginas 61 e 62, encontra um quadro com dez estudos de reconhecimento da emoção alheia, também se descreve o tipo de emoção estudada, o(s) autor (s), o método utilizado na pesquisa e a idade dos sujeitos; em seguida a autora procede uma revisão dos estudos da autopercepção da emoção em crianças. Finalmente, na página 82 , brinda-nos com um quadro do "Resumo da evolução emocional infantil", descrevendo a idade e a experiência/reconhecimento, de 0-12 meses, 18 meses, 2 anos, 2-3anos, 2-4 anos, 4-5 anos, 6-7 anos e 7 anos.

No capítulo 3 nos apresenta "Aspectos sociales de la emoción infantil". Faz considerações sobre o apego como via da instalação emocional da criança, descreve os tipos de apego e as conseqüências do apego no comportamento emocional da criança. Na página 99, cita uma revisão sobre apego realizada por Lafuente (2000), segundo a qual uma adequada relação afetiva produz na criança os seguintes efeitos: melhor desenvolvimento intelectual, melhor linguagem, habilidade para jogos simbólicos, melhor desenvolvimento metacognitivo, maior flexibilidade e realismo no processamento da informação, mais inteligência social, melhor habilidade leitora entre outros. Descreve as condições ótimas dos pais para um bom desenvolvimento do apego e afirma que os estudos são predominantemente relacionados à díade mãe-filho.

Como avaliar emoções em crianças? Este é o assunto abordado no capítulo 4, com o título: "La evaluación de las emociones en el niño". Depois dos sete ou oito anos, as emoções podem ser avaliadas de maneira muito semelhante à realizada com adultos, mas como proceder com crianças menores quando ainda não desenvolveram um repertório verbal nem suficientes habilidades motoras? Na página 106, a autora elenca as estratégias de observação mais habituais. Nas páginas seguintes apresenta as modalidades mais objetivas de avaliação emocional, descreve: níveis hormonais, eletrocardiograma, eletroencefalograma e eletromiograma. Depois do terceiro ano de vida, é possível propor tarefas para identificação de emoções e a autora cita as seguintes estratégias: 1) Escolha de fotos frente a determinadas emoções, cita o teste de Denham (1986) Affective 
Labeling Task para avaliar a capacidade da criança em reconhecer emoções; 2) Reconhecimento de emoções em personagens de história narrada e 3) Reconhecimento de emoções representadas mediante jogos, cita o Affect in Play Scale (Howe \& Silvern, 1981). Na página 137 apresenta seis instrumentos para avaliação de competência emocional, descrevendo o título, autor(es), tipo de tarefa e a idade a que se aplica, e em seguida, apresenta dois quadros, um cita os instrumentos genéricos com um fator de desenvolvimento emocional e no outro apresenta instrumentos de avaliação de emoções específicas, tais como: ansiedade, depressão e medo.

No capítulo 5, "Las emociones más relevantes en el niño", a autora apresenta uma revisão dos estudos mais relevantes de que atualmente se dispõe sobre as emoções básicas: medo, ira, tristeza, alegria e amor. $\mathrm{Na}$ página 147 apresenta uma tabela de medos evolutivos segundo Jersild (s/d) e prossegue com comparações da análise de outros autores.

O último capítulo: "La prevención de los problemas emocionales", é iniciado com a afirmativa:

Cuando las emociones no se expresan, no se dominan o no se adecuan a la situación del entorno aparecen las disfunciones. El desajuste emocional infantil se presenta cuando hay falta de oportunidad o adecuación de las reacciones propias o cuando hay mala interpretación de las emociones de los otros... (p. 169)

Segundo a Dra. Del Barrio, os pais são fundamentais na prevenção de problemas emocionais infantis, pois são as pessoas que melhor conhecem e mais tempo passam com a criança e, também, pelos laços afetivos mais fortemente estabelecidos. No processo de socialização da criança, os estilos parentais, são fundamentais e no que diz respeito à educação sentimental três pilares são essenciais: modelação, treinamento e manejo de contingências. A autora aborda essas três estratégias parentais e apresenta dados de pesquisas. Conclui o capítulo esclarecendo quando se torna necessário recorrer a uma ajuda profissional, afirmando que o fracasso da prevenção primária dos problemas emocionais passa a demandar a ajuda de profissionais especializados.

Entre o último capítulo e as leituras recomendadas há o epílogo, na página 184 a autora afirma: "Como se ve, ser inteligente emocionalmente supone ser adaptativo em la canalización de la energía de acción que uma emoción brinda a los sujetos. Es decir, que la emociones, al cabo, son uma llave esencial que abre el camino de la inteligencia y también la vía para la felicidad".

Cinco são as leituras recomendadas, após cada sugestão a autora oferece um comentário ou análise do material. São listadas as seguintes leituras:

1) Denham, S. A. (1998). Emotional development in Young children. Nova Cork: Guilford Press.

2) Harris, P. L. (1992). Los niños y la emociones. Madri: Alianza.

3) Mascolo, M. F. \& Griffin, S. (1998). What develops in emotional development? Nova York: Plenum Press.

4) Watson, J. B. \& Morgan, J. J. B. (1917). Emotional reactions and psychological experimentation. American Journal of Psychology, 28, 163-174.

5) Woodhead, M.; Barnes, P.; Miell, D. \& Oates, J. (1995). Developmental perspectives on emotion. Em P. Barnes (Org.), Personal, social and emotional development of children. Oxford: Blackwell Publisher.

Este livro é leitura essencial para pesquisadores que se ocupem do universo da infância $e$ especialmente para aqueles que desejem saber mais sobre as emoções infantis. Leitura acessível, pois existem muitos quadros e tabelas com a síntese dos principais estudos realizados na área; obra didática e fonte de muitas referências. A obra tem o estilo de sua autora, simples e agradável na forma sem deixar de ser ampla e profunda no conteúdo.

Enviado: 10.03.2004 Revisado: 10.06 .2004 Aceito: 15.06.2004

\section{Sobre o autor da resenha:}

Cloves Amorim: Psicólogo, Doutorando em Psicologia Básica na Universidade Complutense de Madrid, Professor do Curso de Psicologia da PUCPR 